\title{
Kinetic of the Intermetallic Phases Growth in the Al Alloy - Ni Composite
}

Alena Michalcová, Anna Teichmanová, Anna Knaislová, Zdeněk Kačenka, Ivo Marek, Dalibor Vojtěch Department of Metals and Corrosion Engineering, University of Chemistry and Technology in Prague, Technická 5, Praha 6, 166 28. Czech Republic. E-mail: michalca@vscht.cz

This article describes the kinetic of intermetallic phases growth during annealing of Al alloy - Ni composite material. The composite was prepared by spark plasma sintering processing (SPS) from gas atomized AlCr6Fe2Si1 with 5 wt. $\%$ of Ni. The composite material is stable at temperatures up to $400{ }^{\circ} \mathrm{C}$ and no formation of intermetallic phases was observed even after $100 \mathrm{~h}$ of annealing. At higher temperatures, the intermetallic phases are formed and the time of the first observation of the intermetallics is strongly dependent on temperature. The only intermetallic phase that was proven by the $\mathrm{XRD}$ was the $\mathrm{NiAl}_{3}$. The content of other intermetallic phases, that were clearly visible on the SEM micrographs, was probably lower than the detection limit of the XRD. The forming layers of intermetallics served not as a protective barrier and the reactions continued until the whole amount of Ni reacted, as was established by observation of the sample annealed for $100 \mathrm{~h}$ at $550{ }^{\circ} \mathrm{C}$.

Keywords: Al alloys, Intermetallics, SPS, self- healing

\section{Introduction}

Rapidly solidified aluminium alloys are promising materials with increased strength and resistance to elevated temperatures compared to the common aluminium alloys. It was proven that $\mathrm{AlCr} 6 \mathrm{Fe} 2 \mathrm{Si1}$ alloy prepared by gas atomization can be successfully compacted by hot extrusion [1], spark plasma sintering [2] and high-pressure spark plasma sintering [3]. All these compact materials exhibit good mechanical properties and thermal stability up to $450{ }^{\circ} \mathrm{C}$ [1].

The formation of intermetallic phases in the $\mathrm{Al}-\mathrm{Ni}$ system is effortless and can be performed even in the air atmosphere [4]. This fact provides a background to one of the possible self-healing mechanisms in the aluminium alloys which mechanism is illustrated in Fig. 1.

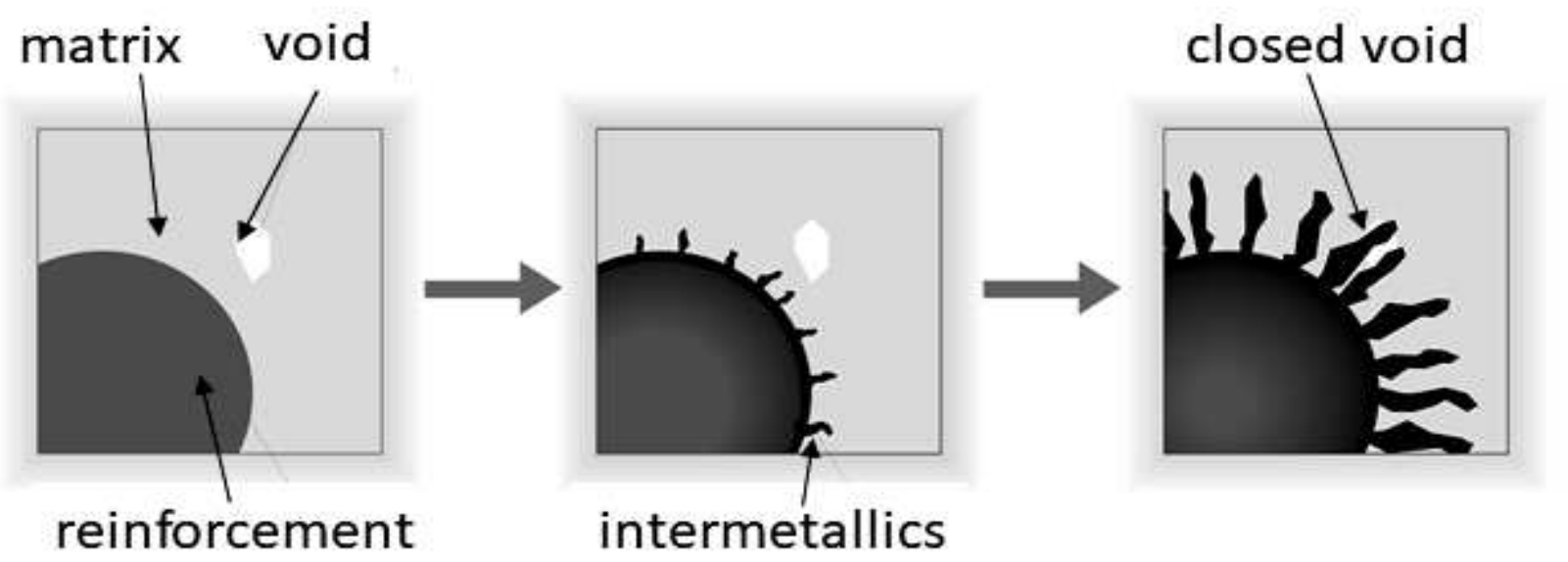

Fig. 1 Schematic drawing of self-healing mechanism by intermetallic phase formation

In the $\mathrm{Al}$ alloy - $\mathrm{Ni}$ composite material, the intermetallic phases are growing under the temperature of $550{ }^{\circ} \mathrm{C}$. The intermetallic phases are growing in the concentric layers around $\mathrm{Ni}$ core with different stoichiometry. The phase which is in touch with $\mathrm{Al}$ matrix is the $\mathrm{NiAl}_{3}$ and grows in radial dendrites. These dendrites are closing cracks and voids in the material and are responsible for the self healing behaviour [5].
The topic of this paper is to study the kinetic aspect of this process. The information about the precise time of intermetallic formation will help to optimize the heat treatment process for closing of the cracks.

\section{Experimental}

The alloy with composition of Al- 6 wt. \% Cr- 2 wt. $\% \mathrm{Fe}-1$ wt. $\%$ Si was prepared by melting appropriate 
amount of pure metals. Subsequently the alloy was processed by gas atomization. The powder was mixed with 5 wt. $\%$ of gas atomized $\mathrm{Ni}$ and the mixture was sintered by SPS (FCT HP D10) at $500{ }^{\circ} \mathrm{C}$ with duration of 15 min. Bulk samples were observed by SEM (TESCAN VEGA 3 LMU) and phase composition was measured by XRD (PANanalytical X'Pert PRO, Co lamp). The annealing was performed at 400, 450, 500 and $550{ }^{\circ} \mathrm{C}$ and it lasted for $0.1,0.25,1,10$ and $100 \mathrm{~h}$ for each temperature.

\section{Results and discussion}

The initial material was formed by $\mathrm{Al}$ matrix, $\mathrm{Al}_{13} \mathrm{Cr}_{2}$ and $\mathrm{Al}_{13} \mathrm{Fe}_{4}$ intermetallic phases and $\mathrm{Ni}$ particles, as shown in Fig. 2. The conditions of the SPS compaction did not lead to the formation of any intermetallic phase on the boundary between $\mathrm{Al}$ based matrix and Ni particles.

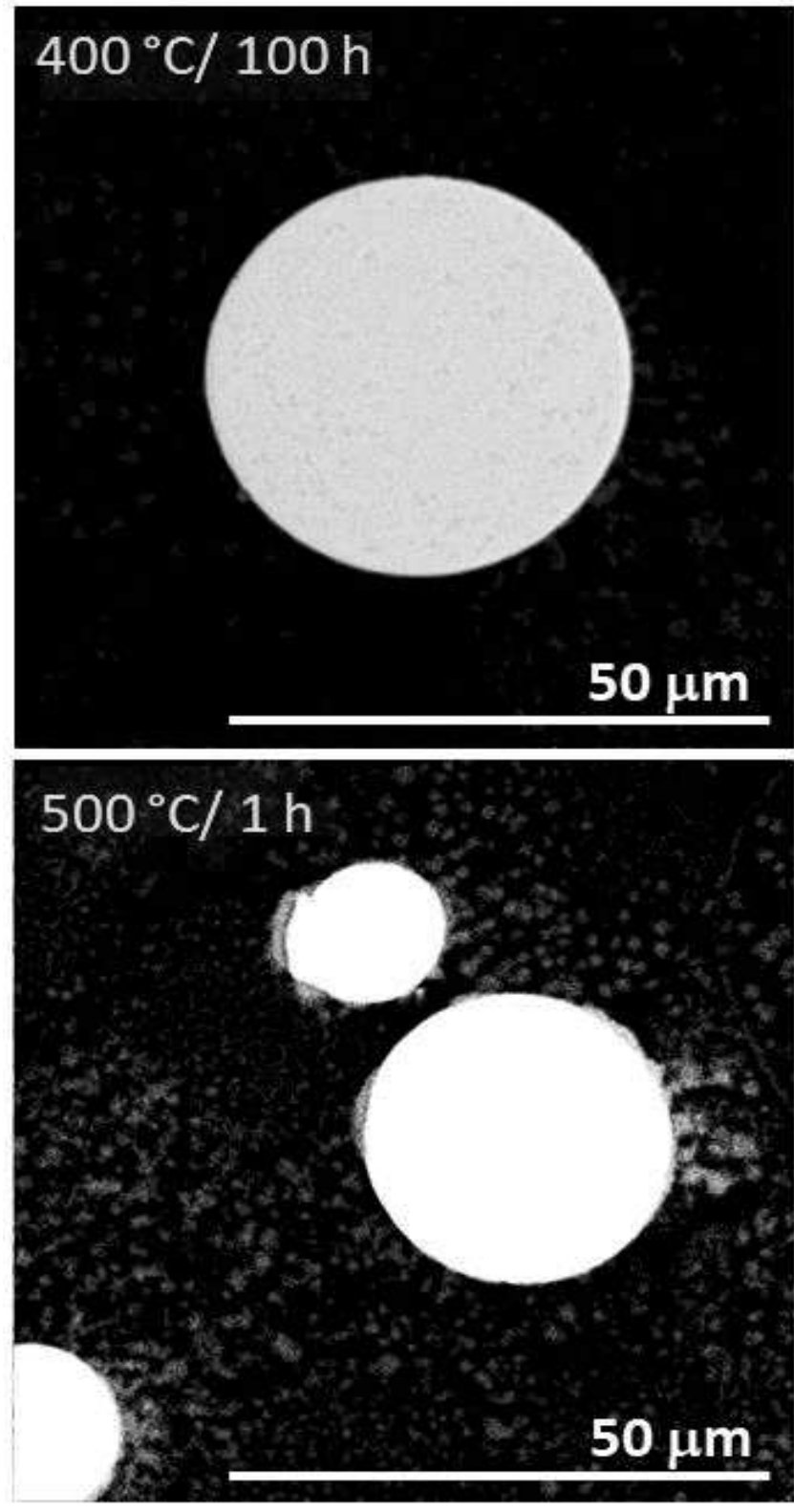

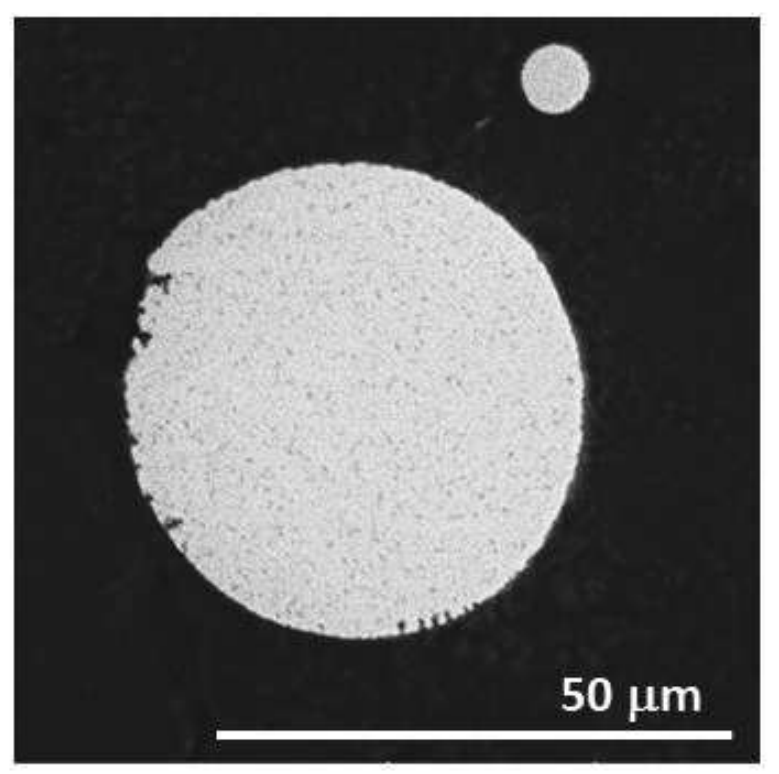

Fig. 2 Microstructure of the initial material (SEM)
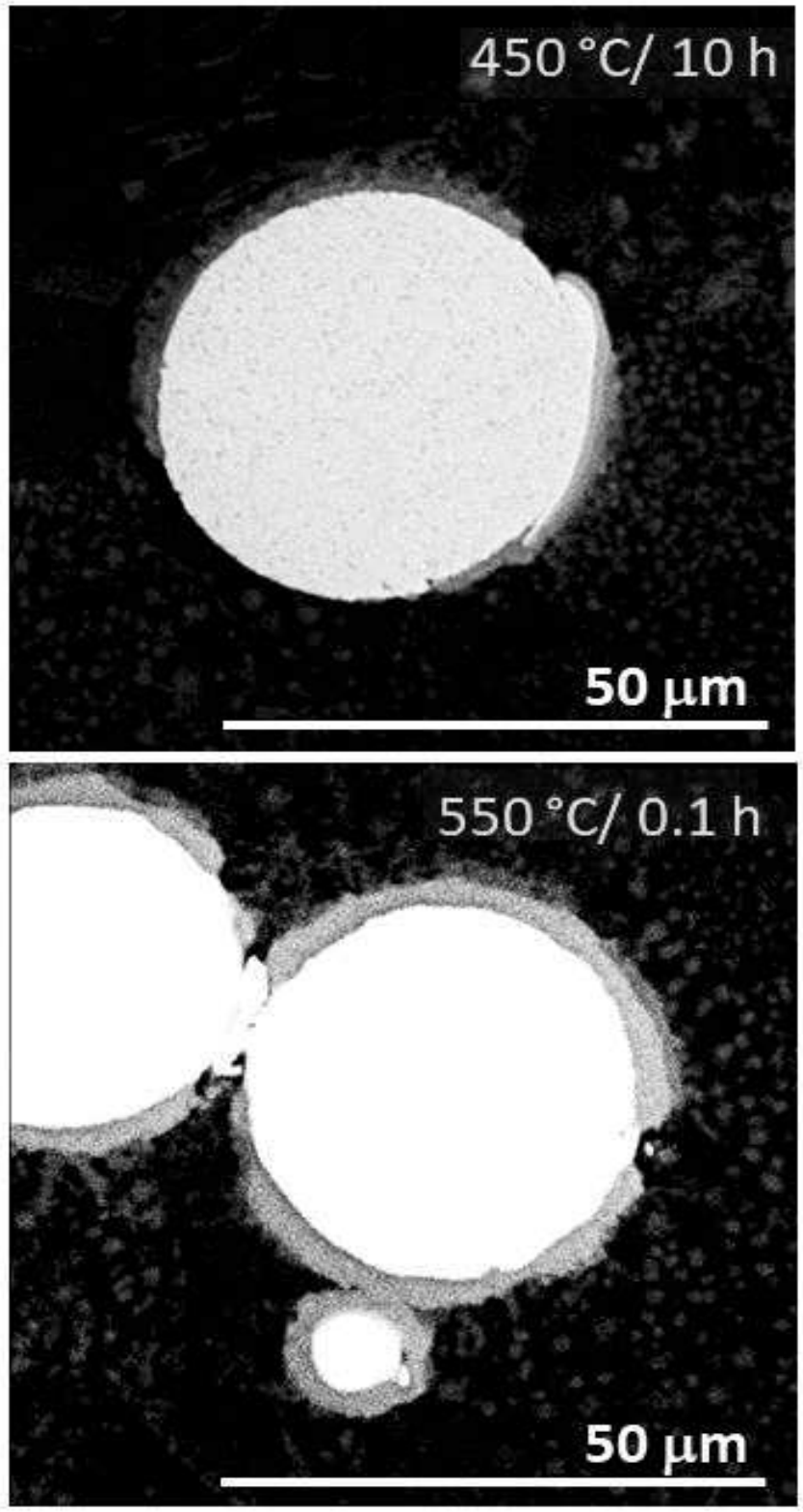

Fig. 3 Microstructure of materials after first intermetallic phases occurrence after annealing at different temperatures 
The time necessary for the occurrence of intermetallic phases was different for each temperature. At the lowest temperature $\left(400{ }^{\circ} \mathrm{C}\right)$, the phases were not observed even after $100 \mathrm{~h}$ of annealing, see Fig. 3. This proves excellent thermal stability of the material. It also shows that the material could be used up to this temperature without unwanted degradation.

The first occurrence of the intermetallic phase was observed after $10 \mathrm{~h}$ during annealing at $450{ }^{\circ} \mathrm{C}$. This fact has two consequences: The material is not suitable for long-term exposition at this temperature due to the
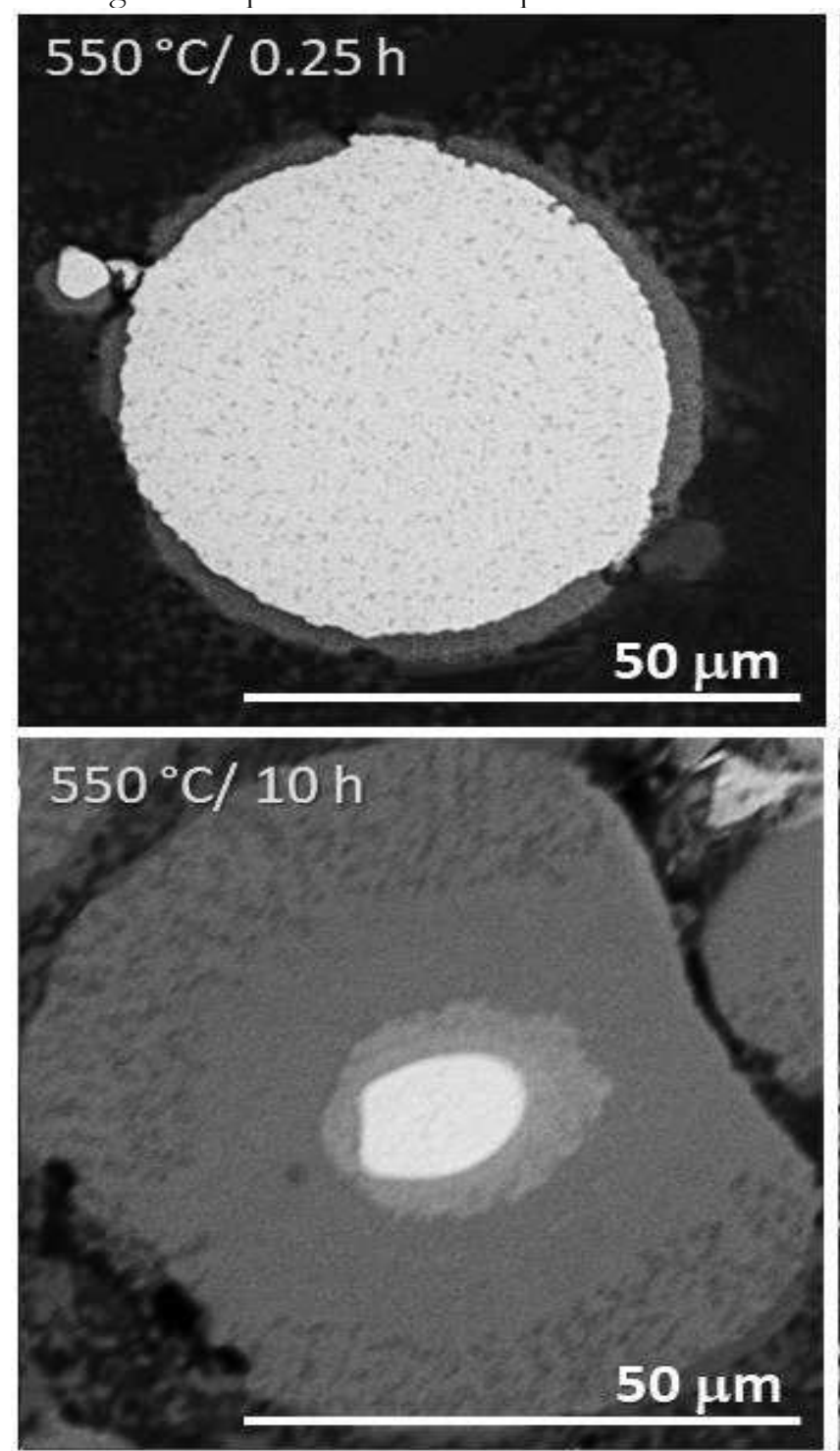

Fig. 4 Microstructure of material annealed at $550^{\circ} \mathrm{C}$ with different duration

As shown in Fig. 4, the growth of intermetallic phases continued with time of annealing. After $0.25 \mathrm{~h}$, the layer of intermetallic phases was still not sufficient. After annealing for $1 \mathrm{~h}$, the complex shell structure was observed. On the boundary of the residual Ni particle, the NiAl phase is located. The following compact phase is $\mathrm{Ni}_{2} \mathrm{Al}_{3}$ and the phase formed by dendrites growing in the $\mathrm{Al}$ matrix is the $\mathrm{NiAl}_{3}$. The phase composition was evaluated based on measuring of local chemical composition by the EDS. The XRD proved intermetallic phases formation. On the other hand, the time to intermetallic phase formation is too long to be applicable for self healing of the material. During the annealing at $500{ }^{\circ} \mathrm{C}$, the very first intermetallic phases were observed after $1 \mathrm{~h}$. Although, the time for the intermetallic phases formation is shorter, the outcomes are the same as described earlier for the temperature of $450^{\circ} \mathrm{C}$. The situation is different for the temperature of $550{ }^{\circ} \mathrm{C}$. The first intermetallic particles were observed after $0.1 \mathrm{~h}$ (6 min.) of annealing.
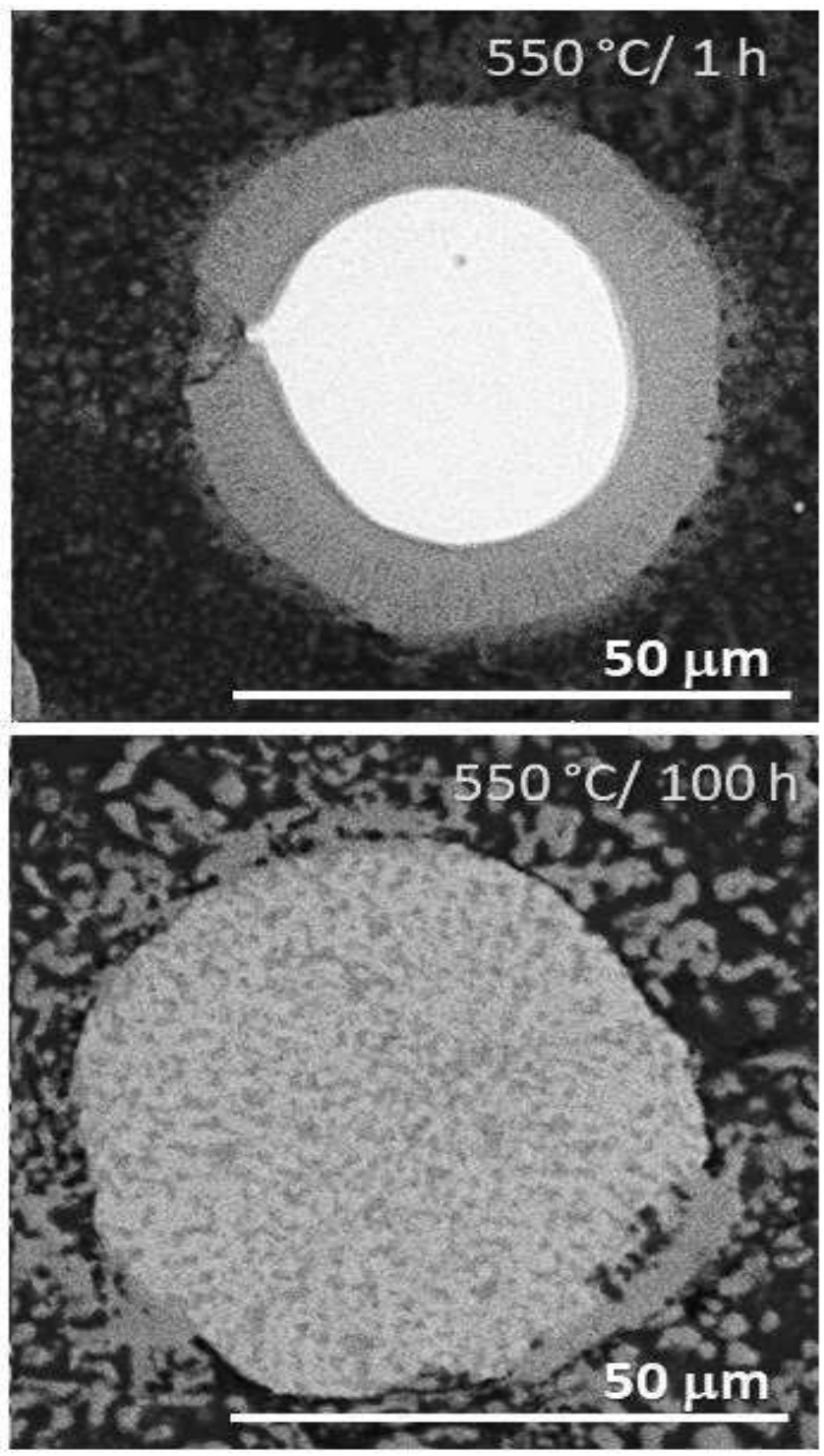

only presence of $\mathrm{NiAl}_{3}$, as shown in Fig. 5. The content of other phases is probably under the detection limit. The increase of annealing time from $1 \mathrm{~h}$ to $10 \mathrm{~h}$ only increased the amount of $\mathrm{NiAl}_{3}$. After $100 \mathrm{~h}$ of annealing, the $\mathrm{Ni}$ completely reacted forming $\mathrm{NiAl}_{3}$ phase. The material approached the equilibrial state. According to Al-Ni phase diagram [6], the alloy with 5 wt. $\%$ of Ni should be formed of eutectic of $\mathrm{Al}$ and $\mathrm{NiA}_{13}$. 


\section{Phase composition after annealing at $500{ }^{\circ} \mathrm{C}$}

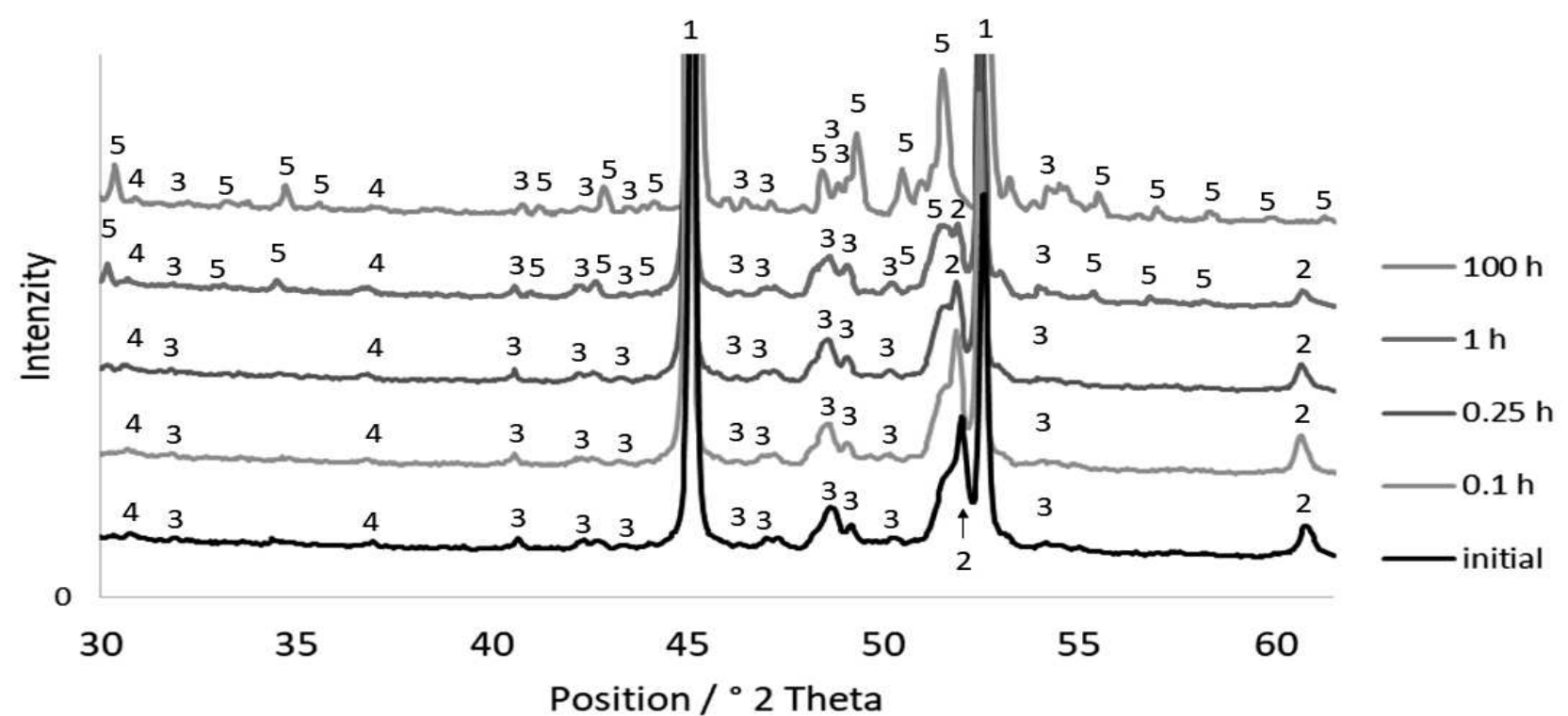

Fig. 5 Phase composition of material annealed at $550{ }^{\circ} \mathrm{C}$ with different duration (1-Al, 2- Ni, 3- Al13Cr2, 4- All3Fe4, 5NiAl3)

Although the intermetallic phases were observed after $0.1 \mathrm{~h}$ of annealing, they were detected by XRD in samples annealed for $1 \mathrm{~h}$ and longer, see Fig. 5.

\section{Conclusion}

In this paper was proven that intermetallic phases in the $\mathrm{Al}$ alloy-Ni system are formed in solid state. The prepared composite material is stable up to $400{ }^{\circ} \mathrm{C}$. The formation of intermetallic phases was observed starting form the temperature $450^{\circ} \mathrm{C}$. The only detected intermetallic phase was $\mathrm{NiAl}_{3}$, although presence of small amounts of phases with different stoichiometry is highly probable. After sufficient time of annealing depending on temperature, the Ni reacted completely.

\section{Acknowledgement}

This work was supported from the grant of Specific university research - grant No A1_FCHT_2020_003.

\section{References}

[1] MICHALCOVÁ, A., VOJTĚCH, D., NOVÁK, P., ŠITTNER, P., PILCH, J., DRAHOKOUPIL, J., KOLAŘ́I, K. (2010). Structure and mechanical properties of an AlCr6Fe2Ti1 alloy produced by rapid solidification powder metallurgy method. In: International Journal of Materials Research, Vol. 101, No.

2, pp. 307-309. Hanser. Germany. ISSN 18625282

[2] KNAISLOVÁ, A., MICHALCOVÁ, A., MAREK, I., VESELKA, Z., VAVŘÍK, J.
(2018). Influence of Sintering Conditions on Compacted Rapidly Solidified AlFeCrSiTi Alloys. In: Acta Physica Polonica A, Vol. 134, No. 3 , pp. 738-742. IFPAN. Poland. ISSN 05874246

[3] KNAISLOVÁ, A., KUČERA, D., MICHALCOVÁ, A., MAREK, I., CYGAN, S., JAWORSKÁ, L. (2018). Microstructure of AlCrFeSi Alloys Prepared by High-Pressure Spark Plasma Sintering. In: Manufacturing Technology, Vol. 18, No. 5, pp. 753-757. UJEP, Czech Republic. ISSN: 1213-2489

[4] MICHALCOVÁ, A., VOJTĚCH, D., KUBATÍK, T.F. NOVÁK, P., DVOŘÁK, P. (2014). Structural Description of Powder Metallurgy Prepared Materials. In: Manufacturing Technology, Vol. 14, No. 3, pp. 359-362. UJEP, Czech Republic. ISSN: 1213-2489

[5] MICHALCOVÁ, A., KNAISLOVÁ, A., KUBÁSEK, J., KAČENKA, Z., NOVÁK, P. (2019). Rapidly Solidified Aluminium Alloy Composite with Nickel Prepared by Powder Metallurgy: Microstructure and Self-Healing Behaviour. In: Materials, Vol. 12, No. 24, 4193. MDPI.

Switzerland. ISSN 1996-1944

[6] OKAMOTO, H. (2019). Supplemental Literature Review of Binary Phase Diagrams: Al-Ni, B-Hf, Ca-Sc, Cr-Sc, Fe-Rh, Hf-Mn, La-Sb, Ni$\mathrm{Re}, \mathrm{Ni}-\mathrm{Sm}, \mathrm{Ni}-\mathrm{Zr}, \mathrm{Sb}-\mathrm{Tb}$, and Ti-Zr. In: Journal of Phase Equilibria and Diffusion, Vol. 40, pp. 830-841. Springer. Germany. ISSN: 1547-7037 